\title{
DINÁMICA DE LA PRODUCCIÓN DE PASTO Y BALANCE FORRAJERO DE UN MÓDULO DE VACAS LECHERAS, EN LA SIERRA CENTRAL
}

\author{
DYNAMIC OF PASTURE PRODUCTION AND FORAGE BALANCE OF DAIRY COWS \\ HERD, IN THE CENTRAL HIGH LANDS
}

\author{
${ }^{1}$ Percy Avalos y ${ }^{2}$ Enrique Flores
}

\begin{abstract}
Resumen
Se condujo un experimento para estudiar la dinámica forrajera, y el contenido de proteínas y energía de una pastura con el propósito de conocer el balance forrajero para un módulo de vacunos lecheros pastoreando una asociación de ryegras-trébol. El área de estudio estuvo localizada a $4200 \mathrm{msnm}$ en Conocancha, SAIS Pachacutec, Junín. La tasa de crecimiento del pasto, y la temperatura y humedad del suelo fueron medidas mensualmente usando jaulas, lapiacos, cuadrantes y termómetros medio-ambientales. Se empleó el análisis Micro-kjelhdal para determinar el contenido proteico del forraje; mientras que la energía metabolizable (EM) fue estimada a partir de la digestibilidad in vitro de la materia orgánica (DIVMO) aplicando la ecuación EM (MJ/KgMS) $=0.16$ x DIVMO (MAFF 1975, citado por Geenty et al., 1987). El balance forrajero fue diseñado con la información anual de la tasa de crecimiento y contenido energético del forraje, y el nivel de producción de leche. Los resultados fueron analizados bajo un diseño completo randomizado con un arreglo factorial de 6 x 2, y la diferencia de medias fue detectada con la prueba de Duncan a un nivel de probabilidad de 0.05 (Calzada 1982). Los resultados revelaron la Dinámica forrajera: los mayores niveles de temperatura y humedad fueron registrados en la estación de verano, lo mismo ocurrió con la tasa de crecimiento del pasto. La temperatura $\left(11.4{ }^{\circ} \mathrm{C}\right)$ siempre estuvo por encima del mínimo requerido $\left(10^{\circ} \mathrm{C}\right)$ para fomentar el crecimiento de la asociación; por otro lado, la humedad del suelo $(28.2 \%)$ no registró niveles cercanos a la capacidad de campo $(60 \%)$. La tasa de crecimiento promedio fue $24.7 \mathrm{KgMS} / \mathrm{ha} /$ día en contraste a $31.5 \mathrm{KgMS} / \mathrm{ha} /$ día encontrado bajo condiciones neozelandesas (Geenty et al., 1987). Contenido de proteína y energía del forraje: la proteína cruda (PC) en base seca fue en promedio $17.1 \%$, mostrándose superior al $10 \%$ mínimo requerido para las dietas de vacas lecheras al pastoreo. El nivel de energía del pasto (7.2 MJ/KgMS) fue menor al mínimo requerido (10 MJ/KgMS, según Bojorquez 1989). Balance forrajero: se registró un déficit forrajero sólo en los meses de abril y julio, y un exceso durante el resto del año. La capacidad de carga potencial promedio fue 2.28 vacas/ha/año, siendo $161 \%$ mayor a la carga actual (1.39 vacas/ha/año).Se concluyó que el factor limitante de la producción de leche bajo las condiciones del estudio es la baja energía del forraje; debido a la aplicación de una reducida capacidad de carga, que origina la acumulación de material muerto e inhibición de la tasa de crecimiento. Se recomienda implementar un sistema de manejo de la pastura que involucre el planeamiento de la rotación de potreros con el número de vacas, y el momento y días de permanencia adecuados, con el objeto de maximizar la tasa de crecimiento del forraje y la ingestión de pasto por parte de las vacas; lo que influenciará positivamente sobre la producción de leche y vida útil de la pastura.
\end{abstract}

Palabras claves: balance forrajero, crecimiento de pasto, energía y proteína.

\begin{abstract}
An experiment was conducted to study ryegrass-clover pasture production dynamics, and protein and energy content to estimate forage balance for dairy cows. The study area was located at 4200 masl in Conocancha, SAIS Pachacutec, Junín. Forage growth rate, soil temperature and soil moisture were measured monthly using exclosure, cutters, frames and enviromental thermometers. Micro-kjelhdal procedures were used to asses protein content of forage; whereas the metabolisable energy (ME) was estimated with the in vitro digestibility of the organic matter (IVDOM) using the ecuation ME $(\mathrm{MJ} / \mathrm{KgDM})=0.16$ x IVDOM (MAFF 1975, cited for Geenty et al. 1987). Forage balance was estimated based on annual information of growth rate, forage energy content and milk production level. The results were analized under a complete randomized design with factorial arrangement six by two, and the difference of means were detected with the Duncan's trial with alpha $=0.05$. The results reveal the Forage production dynamics: higher temperature and moisture soil level were registered during the summer, which were to growth's rates of pasture. The temperature (11.4 ${ }^{\circ} \mathrm{C}$ ) was above the minimum $\left(10{ }^{\circ} \mathrm{C}\right)$ needed to allow forage growth; on the other hand, soil moisture $(28.2 \%)$ was not register near levels of the field capacity $(60 \%)$. The growth rate average was $24.7 \mathrm{KgDM} / \mathrm{ha} /$ day in contrast to 31.5 $\mathrm{KgDM} / \mathrm{ha} /$ day finded under conditions of newzelands pasture (Geenty et al., 1987). Protein and energy content of forage: crude protein $(\mathrm{CP})$ was $17.1 \%$ which was higher than the minimum required $(10 \%)$. In addition, forage energy level $(7.2 \mathrm{MJ} / \mathrm{KgDM})$ was lower than the minimum required for a dairy cow $(10 \mathrm{MJ} / \mathrm{KgDM})$; cited for Bojorquez
\end{abstract}


(1989). Forage balance: there is a deficit of forage between April and July and a surplus the rest year. The potencial stocking rate mean was $2.28 \mathrm{cows} / \mathrm{ha} /$ year, that was $161 \%$ higher the actual stocking rate mean (1.39 cows/ha/year). We concluded that the limited factor of the milk production under the study conditions, is the low energy of the forage because of a reduced stocking rate, that originate the accumulation of dead material and inhibit the growth rate of the pasture. We recommend to implement a pasture management system that involve a paddock rotation with precise number of cows, and adequated moment and permanence days; with the objetive to maximise the growth rate of forage and the ingestion of pasture, that positively influence milk production and the profitable use of the pasture.

Key words: energy, forage balance, pasture growth and protein.

\section{Introducción}

La producción lechera en el Perú se encuentra diferenciada principalmente en dos zonas geográficas: a nivel de la costa peruana (39\%), en la cual hay un uso intensivo de los sub-productos de la agro-industria que permiten un suministro de alimento concentrado durante toda la vida útil y económica de la vaca lechera. Estos alimentos proporcionan la cantidad y calidad de nutrientes necesarios para explotar su potencial genético y maximizar su producción de leche. A nivel de la región alto andina $(54 \%)$ el panorama se muestra distinto; el ganado depende en gran medida de los pastos naturales y en menor grado de las asociaciones vegetales que crecen a expensas de las precipitaciones de intensidad estacional, siendo complementadas con un riego poco eficiente. Pastos de calidad regular, que cubren los requerimientos proteicos durante todo el año, más no las necesidades energéticas de las vacas lecheras, enmascarando la expresión del verdadero nivel productivo. Por otro lado, la mayoría de ganaderos asignan sus canchas de pastoreo en función a sus experiencias empíricas, desconociendo el potencial real de sus pasturas; así como, el techo genético de su ganado lechero. Esto no permite trabajar con eficiencia y por consiguiente el administrador cree que su explotación no le resulta económicamente rentable. Ante lo expuesto se pretende mejorar el aprovechamiento del forraje, enfatizando los pastos cultivados; y maximizar la productividad lechera, al incentivar el uso eficiente de los mencionados pastos en la alimentación de vacunos de leche al pastoreo. Para ello, se evaluará el suministro proteico y energético de la pastura disponible, y los requerimientos alimenticios de las vacas lecheras en función al peso vivo y nivel de producción de leche, para la correcta asignación del área por animal dentro de los potreros de pastoreo. Los objetivos establecidos para el presente estudio incluyen la determinación del patrón de variación de la temperatura y humedad del suelo, y la tasa de crecimiento, contenido de proteína y energía del forraje; así como, el diseño del balance forrajero para el módulo de vacas lecheras del área estudiada.

\section{Materiales y métodos}

El presente estudio se ejecutó en la SAIS Pachacutec Ltda. No 7 del Departamento de Junín a 4200 msnm y el área de trabajo abarcó 35 hectáreas cubiertas por una pastura asociada de gramínea - leguminosa integrada por Dactylys glomerata "pasto ovillo“ (37.8\%), Trifolium repens "trébol blanco" (34.6\%), T. pratense "trébol rojo" (5.7\%), Lolium perenne "ryegras inglés" (17.9\%), L. multiflorum "ryegras italiano" (3.1\%) y especies nativas $(0.9 \%)$. La etapa experimental comprendió los 12 meses del año. Se diseñaron quince jaulas de crecimiento de pasto de $0.64 \mathrm{~m}^{2}$ de superficie $(0.80 \times 0.80)$ de fierro y sus accesorios, dos cuadrantes de $0.25 \mathrm{~m}^{2}$ de área $(0.5 \mathrm{~m}$ x $0.5 \mathrm{~m}$ ) en base a varillas de fierro de $0.5 \mathrm{~cm}$ de diámetro para delimitar el área de corte del pasto, una balanza para el pesado del pasto cortado, dos termómetros para la toma de temperatura del suelo, y vasos plásticos para el muestro del suelo.

Como puntos de referencia para el registro de la temperatura y humedad del suelo, se distribuyeron sistemáticamente quince jaulas de crecimiento a lo largo de la pastura en una sola fila y equidistantes una de otra. Para la toma de la temperatura se seleccionaron de manera intercalada seis de las quince jaulas y se ubicó un punto circundante a cada una de ellas. Ubicado el punto, se cavó un hoyo y a una profundidad de 10 y 20 centímetros de la superficie del suelo se introdujeron los termómetros simultáneamente, permaneciendo no menos de cinco minutos previos a la anotación de la lectura correspondiente. Se obtuvieron muestras de suelo a 10 y 20 centímetros de profundidad y se colocaron en envases plásticos, para su posterior determinación de la humedad utilizando una estufa a $105^{\circ} \mathrm{C}$ por un tiempo de 24 horas (AOAC, 1980).

Las quince jaulas distribuidas sistemáticamente se utilizaron también para la medición de la tasa de crecimiento mensual de la pastura, cortando el pasto crecido con un lapiaco a ras del suelo en un área limitada de $0.25 \mathrm{~m}^{2}$. Los cortes se realizaron a inicios de cada mes en las quince parcelas, siendo éstas inmediatamente protegidas con las respectivas jaulas de crecimiento para excluirlas del pastoreo. Luego de treinta días, el pasto cortado se introdujo en una bolsa y se pesó inmediatamente. Las muestras fueron secadas para determinar su materia seca utilizando una estufa a 60 ${ }^{\circ} \mathrm{C}$ por un tiempo de 48 horas (AOAC, 1980) y por lo tanto el peso seco del pasto crecido durante un mes. El peso seco en gramos fue multiplicado por el factor 40 para calcular el crecimiento logrado en kilogramos por hectárea, y luego fue dividido entre el número de días transcurridos entre corte y corte para así obtener la tasa de crecimiento en kilogramos de materia seca por hectárea y por día (KgMS/ha/día). 
Mensualmente se obtuvieron muestras del pasto disponible de lugares próximos a las jaulas de crecimiento. Las quince muestras de pasto que se obtuvieron mensualmente, luego de haber sido secadas y pesadas, fueron mezcladas homogéneamente para la obtención de una alícuota representativa, la que fue molida y conservada adecuadamente en frascos de vidrio. Al final del experimento se totalizaron doce alícuotas que fueron utilizadas para la determinación del contenido de proteína cruda mediante el método Semi-Micro Kjelhdal, de acuerdo a las normas establecidas por la AOAC (1980). Asimismo, las muestras del pasto disponible fueron sometidas a un análisis de digestibilidad in vitro de la materia orgánica (DIVMO) empleando el Método de Tilley y Terry modificado por Van Soest (1972), a partir del cual se estimó la energía metabolizable (EM) de la pastura por mes, expresada en MJ EM/KgMS, con la aplicación de la siguiente ecuación: $\mathrm{EM}=0.16$ x DIVMO (MAFF, 1975 citado por Geenty et al., 1987).

Para conocer el balance forrajero del módulo lechero de vacas $3 / 4$ Brown Swiss x $1 / 4$ Criollo, se tuvieron que estimar la carga actual (dividiendo el número de vacas del módulo por el área total de la pastura), la demanda de forraje (considerando peso vivo, nivel de producción de leche, requerimiento energético, valor energético del forraje -VEF del pasto y la carga actual), y la oferta de forraje determinada por la tasa de crecimiento del pasto. El balance se estimó comparando la oferta y demanda de forraje; así como, la carga potencial (dividiendo la oferta de pasto por la demanda de forraje) y la carga actual.

\section{Resultados y discusión}

Dinámica de la producción forrajera: en general, no hubo diferencias $(\mathrm{p}>0.05)$ entre la toma de temperatura y humedad a 10 y $20 \mathrm{~cm}$ debajo de la superficie del suelo dentro de un mismo mes. En la Fig. 1 se exhiben las curvas de tendencia de la temperatura y humedad del suelo a lo largo del año. Nótese que en el período de Diciembre a Abril la temperatura y humedad del suelo son significativamente máximas en referencia al resto de los meses a causa de la ausencia de heladas, y frecuencia e intensidad de lluvias y probable riego del área de pasto cultivado, respectivamente; aun cuando la tasa de evapotranspiración pudiera ser la máxima durante ésta época del año. Por otro lado, entre el período de Mayo a Noviembre se observa una tendencia decreciente de la temperatura y humedad, en referencia a la estación de verano, a consecuencia de las fuertes heladas, y ausencia de lluvias, alta intensidad luminosa y probable no programación de riego. La humedad del suelo (28.2\%) registró niveles por debajo de la capacidad de campo $(60 \%)$. Korte et al. (1987), indica que la temperatura afecta directamente la habilidad de las plantas para convertir los azúcares en tejido vegetal durante el crecimiento, por lo tanto las temperaturas por debajo de los $10{ }^{\circ} \mathrm{C}$ durante el otoño invierno o época de sequía limitan la conversión de dichos azúcares, exhibiéndose un crecimiento mínimo del pasto.
Lo contrario ocurre durante fines de primavera - verano o época lluviosa en donde el pasto crecido es óptimo debido al incremento de la temperatura y disponibilidad de humedad en el suelo.

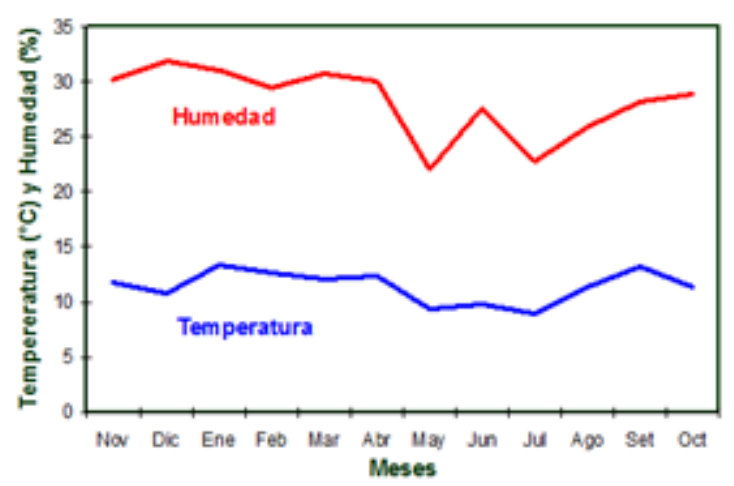

Figura 1. Variación anual de la temperatura y humedad del suelo.

Para que la producción de pasto sea máxima se requiere de una temperatura por encima de los $10{ }^{\circ} \mathrm{C}$ y humedad cercana a la capacidad de campo, con un probable incremento de hasta $8 \mathrm{KgMS} / \mathrm{ha} /$ día en la tasa de crecimiento por aumento de un grado celsius en la temperatura y humedad, significando la disminución de cualquiera de ellos una causa de la reducción del crecimiento del pasto en $4 \mathrm{KgMS} /$ ha/día (Baars, 1980 y Radeliffe y Baars, 1986; citado por Korte et al., 1987). Es importante mencionar que los ryegrases y tréboles componentes de la asociación en estudio son especies que no toleran la sequía, razón por la cual durante los períodos de escasa humedad del suelo son ellos los que van a verse reducidos en su crecimiento de manera más detrimental con respecto al dactylis. Este último sí tolera la sequía y aporta la mayor cantidad de forraje ofertado por la pastura durante el otoño - invierno. Cabe indicar también, que el contenido de humedad del suelo, al momento de realizar las evaluaciones, no llegó ni al $55 \%$ de la capacidad de campo; haciendo relucir que existe una inadecuada práctica de riego no permitiendo que las plantas, independientemente de su tolerancia a la sequía, maximicen la tasa de crecimiento y vigor, y por consiguiente el rendimiento forrajero.

Las mayores tasas de crecimiento (KgMS/ha/día), según la Fig. 2, ocurrieron en Diciembre (29.2), Enero (27.2), Febrero (47.2) y Marzo (24.3); lo cual coincidió con los mayores reportes de humedad y temperatura del suelo. Asimismo, se percibió un crecimiento mínimo durante Julio (11.9), Agosto (13.0) y Setiembre (17.4) e irregular durante Abril (21.2), Mayo (22.7), Junio (29.0), Octubre (33.1) y Noviembre (19.7); ya que el momento del inicio y término del período de lluvias e intensidad de heladas varía de año a año. Por otro lado, la tasa de crecimiento se puede predecir, a pesar de su gran variabilidad (Naupari y Flores, 2000), mediante la generación de modelos matemáticos de crecimiento a partir de la temperatura 
y humedad del suelo, variables de las que depende directamente; no obstante existen otros factores -como el manejo- que se suman a los ya indicados, pero que pueden ser controlados y por lo tanto obviados.

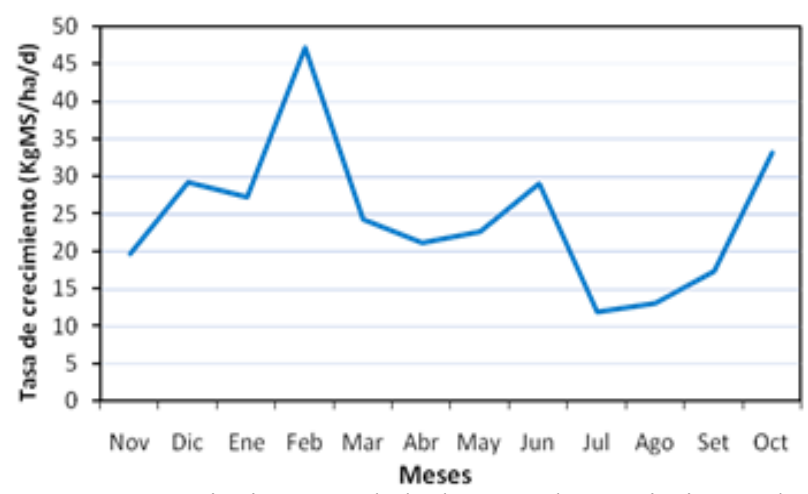

Figura 2. Variación anual de la tasa de crecimiento de pasto.

Valor proteico y energético del pasto: La variación anual en el contenido de proteína cruda y energía metabolizable del pasto disponible en la pradera cultivada se presenta en la Fig. 3. La proteína reportó sus mayores niveles en los meses de Setiembre y Enero, manteniéndose más constante durante Diciembre, Octubre, Noviembre, Marzo, Febrero y Mayo. El descenso de la proteína fue detectado en Abril, Junio, Julio y Agosto. Los valores encontrados (15.5 a 23.5\%) son similares a los datos reportados por Acuña et al. (1978), para una asociación ryegras/trébol, que van del $14 \%$ al inicio de floración al $24 \%$ en brotes con hojas pequeñas. Las leguminosas de la asociación mejoran la calidad de la pastura a través del incremento de la proteína cruda en contraste con la gramínea sola (San Martín et al., 1974 y 1980), permitiendo encontrar niveles que están por encima del $10 \%$ requerido por vacas lecheras de alta producción (Bojorquez, 1989) y no siendo una limitante en la cría de ganado lechero. La disminución del contenido de proteína cruda durante el invierno es atribuido a la inhibición parcial de la tasa de crecimiento de los tréboles por la reducida temperatura y humedad del suelo, siendo ellos los que aportan más porcentaje de proteína a la asociación (Bojorquez, 1989), pero aún así, siempre está por encima del nivel mínimo requerido por las vacas.

La energía metabolizable (EM) tiene una tendencia similar a la mostrada por la proteína cruda, correspondiendo su máximo valor en Enero (8.7 MJ EM/KgMS) y el mínimo en Abril (5.8 MJ EM/KgMS). Estos valores están por debajo de aquellos publicados por Geenty y Rattray (1987) para pasturas en condiciones neozelandezas, calculados a partir de diferentes porcentajes de digestibilidad, variando de 8.8 a $12.8 \mathrm{MJ}$ EM/KgMS. Para una pastura de ryegras/ trébol blanco que se asemeja en composición de especies a la asociación en estudio, se reporta a nivel de hojas, un rango de 15.0 a $25.0 \%$ de proteína cruda y 12.0 a 13.3 MJ EM/KgMS (Geenty y Rattay, 1987). El nivel de energía promedio del pasto (7.2 $\mathrm{MJ} / \mathrm{KgMS})$ fue menor al mínimo requerido por vacas lecheras (10 MJ/KgMS; según Bojorquez, 1989). Los bajos valores de energía metabolizable obtenidos pueden deberse probablemente a la baja carga animal aplicada (estimada en 1.39 vacas/ha), que conlleva a eventos de sub-utilización de la pastura; y a la lenta velocidad de rotación que hace que las vacas ingresen a los últimos potreros cuando el pasto se encuentran en un estado fenológico de sobremaduración. Es más, la digestibilidad está directamente ligada al contenido de energía del pasto, determinando en muchos de los casos el nivel de consumo por parte de las vacas e incidiendo positivamente sobre la ganancia de peso y rendimiento de leche (Bojorquez, 1989). Por ello, es crucial rotar los potreros de pastoreo cuando la pastura se encuentra en un estado vegetativo de hojas tiernas y antes de la floración, eventos fenológicos donde la proteína cruda, digestibilidad y energía metabolizable son máximas; en tanto que el contenido de fibra cruda es bajo.

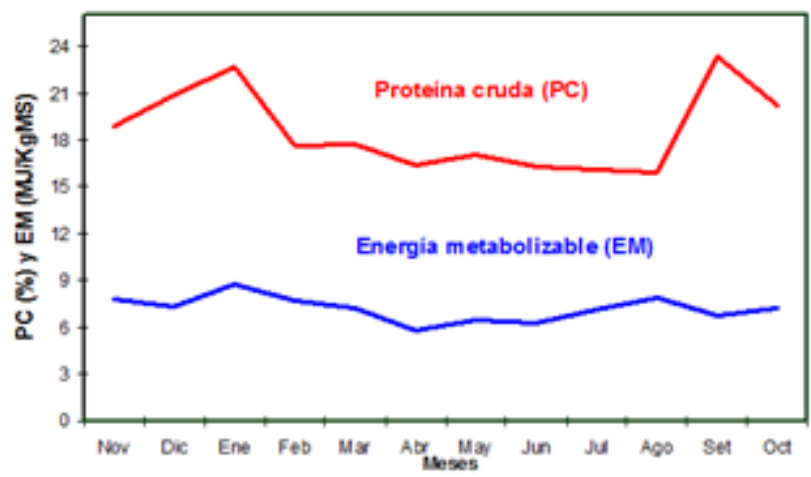

Figura 3. Variación anual de proteína cruda y energía del pasto.

Balance forrajero: el balance forrajero para el módulo lechero de la U.P. Conocancha se presenta en la Tabla 1 , el cual revela una carga actual promedio de 1.39 vacas/ha, la misma que fue variable a lo largo del año. Al comparar la oferta (crecimiento de pasto) y demanda actual, se observó que la demanda de forraje superaba a la oferta (en Abril, -2.21 KgMS/ha/día; y Julio, -0.54 $\mathrm{KgMS} / \mathrm{ha} /$ día); mientras que en el resto de meses la oferta fue superior a la demanda. La baja carga actual o sub-utilización ocasiona la maduración del pasto, por lo que se tienen bajos valores energéticos del forraje -VEF (más aún cuando las muestras analizadas fueron producto del muestreo del pasto disponible). Al realizar el ajuste de la carga mensual, en base al balance de la oferta de pasto y demanda animal, se obtuvo un promedio de carga potencial de 2.28 vacas/ha, obviamente con variaciones mes a mes, evidentemente superior a la carga actual en 0.89 vacas/ha como diferencial promedio. 
Tabla 1. Balance forrajero para un módulo de vacas lecheras, en la UP Conocancha ${ }^{(1)}$.

\begin{tabular}{|c|c|c|c|c|c|c|c|c|c|c|c|c|}
\hline Variable/Mes & Nov & Dic & Ene & Feb & Mar & Abr & May & Jun & Jul & Ago & Set & Oct \\
\hline Número de vacas del módulo & 57 & 45 & 55 & 49 & 53 & 60 & 48 & 39 & 42 & 46 & 45 & 45 \\
\hline Carga actual, vacas/ha & 1.63 & 1.29 & 1.57 & 1.40 & 1.51 & 1.71 & 1.37 & 1.11 & 1.20 & 1.31 & 1.29 & 1.29 \\
\hline Producción de leche, lt/vaca/día & 3.00 & 3.20 & 3.30 & 3.60 & 4.00 & 3.80 & 4.40 & 4.40 & - & - & 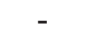 & 4.20 \\
\hline $\begin{array}{l}\text { Requerimiento }{ }^{(2)}, \mathrm{MJEM} / \text { vaca/ } \\
\text { día }^{(3)}\end{array}$ & 78.00 & 78.30 & 78.50 & 78.90 & 79.50 & 79.20 & 80.10 & 80.10 & 73.60 & 73.50 & 73.5 & 9.8 \\
\hline $\begin{array}{l}\text { VEF(4) del forraje, MJEM/ } \\
\text { KgMS }\end{array}$ & 7.80 & 7.30 & 8.70 & 7.70 & 7.20 & 5.80 & 6.50 & 6.30 & 7.10 & 7.90 & 6.70 & 7.2 \\
\hline Asignación, KgMS/vaca/día & 10.00 & 10.73 & 9.02 & 10.25 & 11.04 & 13.66 & 12.32 & 12.71 & 10.37 & 9.30 & 10.9 & 11.0 \\
\hline Demanda, KgMS/ha/día & 16.29 & 13.79 & 14.18 & 14.35 & 16.72 & 23.41 & 16.90 & 14.17 & 12.44 & 12.23 & 14.1 & 14.2 \\
\hline Ofe & 19.70 & 29.20 & 27.20 & 47.20 & 24.30 & 21.20 & 22.70 & 29.00 & 11.90 & 13.00 & 17.40 & 33.1 \\
\hline $\begin{array}{l}\text { Balance, KgMS/ha/día } \\
\text { Carga potencial, vacas/ha }\end{array}$ & $\begin{array}{l}3.41 \\
1.97\end{array}$ & $\begin{array}{l}15.41 \\
2.72\end{array}$ & $\begin{array}{l}13.02 \\
3.01\end{array}$ & $\begin{array}{c}32.85 \\
4.61\end{array}$ & $\begin{array}{l}7.58 \\
2.20\end{array}$ & -2.21 & 5.80 & $\begin{array}{l}14.83 \\
2.28\end{array}$ & $\begin{array}{l}-0.54 \\
1.15\end{array}$ & $\begin{array}{l}0.77 \\
1.40\end{array}$ & $\begin{array}{l}3.30 \\
1.59\end{array}$ & $\begin{array}{l}18.85 \\
2.99\end{array}$ \\
\hline Diferencial de carga, vacas/ha & 0.34 & 1.44 & 1.44 & 3.21 & 0.69 & -0.16 & 0.47 & 2.2 & -0.05 & 0.08 & 0.30 & \\
\hline
\end{tabular}
Area

(1) Peso vivo promedio de vacas del módulo lechero: $400 \mathrm{~kg}$

(2) MJ EM: Mega joules de energía metabolizable

(3) VEF: Valor energético del forraje

En el balance anual de la oferta y demanda de pasto (Fig. 4) se observa claramente que en gran parte del año (Noviembre a Marzo, Mayo a Junio, y Agosto a Octubre) existió un periodo de excedente, y otra pequeña parte del año (Abril y Julio) un déficit de pasto. Esto nos conlleva a la decisión de incrementar la carga en los meses de abundancia, y bajar la carga o suplementar en los meses de déficit; a fin de realizar una mejor planificación de la alimentación. Para las puntuales y pequeñas brechas de déficit en los meses de abril y julio, se podrían trasladar las vacas a pastos naturales de condición buena o excelente o suplementarlas con heno o ensilado preparado a partir del excedente de los otros meses o simplemente comprarlo.

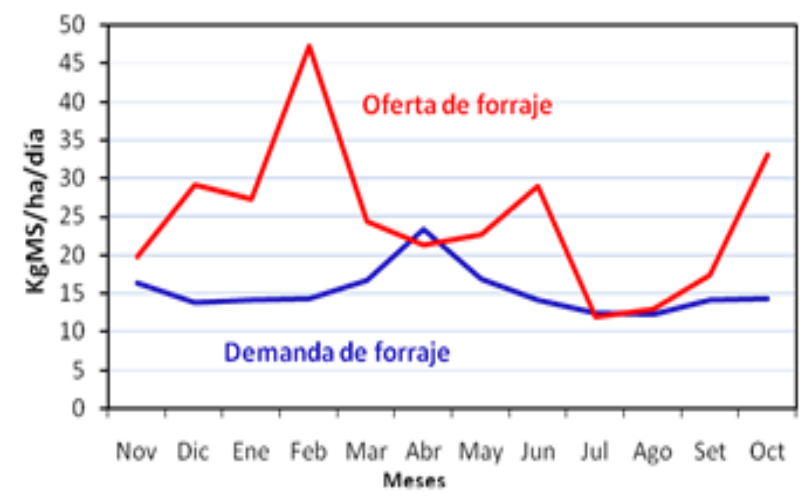

Figura 4. Balance anual entre la oferta y demanda animal de pasto.

Dado que en general, se evidencia en el módulo estudiado un exceso de forraje en gran parte del año, se ha estimado la cantidad de vaquillas de aproximadamente $150 \mathrm{~kg}$ de peso vivo que pueden alimentarse en el módulo en tres periodos establecidos: noviembre a marzo (hasta 2 vaquillas), mayo a junio ( 8 vaquillas) y agosto a octubre (3 vaquillas); tal como se muestra en las Tablas 2 y 3 .
Tabla 2. Valores requeridos para el cálculo de vaquillas adicionales por periodo.

\begin{tabular}{|c|c|c|c|c|}
\hline \multirow{3}{*}{ Periodo } & \multicolumn{4}{|c|}{ Cálculos para el periodo } \\
\hline & \multirow{2}{*}{$\begin{array}{l}\text { Crecimiento } \\
\mathrm{KgMS} / \mathrm{ha} / \text { día }\end{array}$} & \multirow{2}{*}{$\begin{array}{c}\text { Carga } \\
\text { actual } \\
\text { Vacas/ } \\
\text { día }^{(1)}\end{array}$} & \multicolumn{2}{|c|}{$\begin{array}{c}\text { Requerimiento de MS/ } \\
\text { día }\end{array}$} \\
\hline & & & $\begin{array}{c}\mathrm{KgMS} / \\
\text { vaca has }\end{array}$ & $\begin{array}{l}\mathrm{KgMS} / \\
\text { vaquilla }^{(2)}\end{array}$ \\
\hline$\overline{\text { Nov-Mar }}$ & 147.60 & 1.48 & $51.04 \quad 75.54$ & 25.52 \\
\hline May-Jun & 51.70 & 1.24 & $25.04 \quad 31.12$ & 12.52 \\
\hline Ago-Oct & 63.50 & 1.30 & $31.36 \quad 40.62$ & 15.68 \\
\hline
\end{tabular}

(1) Consumo de vaquillas de $150 \mathrm{~kg}$, estimado como el 50\% del consumo de vacas; a partir de Naupari (2000).

Adicionalmente al óptimo aprovechamiento de la pastura, se permitirá que las vaquillas incluidas al sistema inicien más pronto su etapa reproductiva y se incorporen al módulo lechero como reemplazos o incremento de la población lechera.

Tabla 3. Cálculo del número de vaquillas a incorporarse en el módulo, por periodo.

\begin{tabular}{|c|c|c|c|}
\hline Variables/Periodo & Nov-Mar & May-Jun & Ago-Oct \\
\hline $\begin{array}{l}\text { Disponibilidad inicial, } \\
\mathrm{KgMS} \mathrm{ha}^{(1)}\end{array}$ & $1,495.30$ & $3,936.00$ & $1,677.30$ \\
\hline $\begin{array}{l}\text { Crecimiento, KgMS/ } \\
\text { ha }^{(2)}\end{array}$ & $4,428.00$ & $1,551.00$ & $1,905.00$ \\
\hline $\begin{array}{l}\text { Disponibilidad } \\
\text { crecimiento, KgMS/ha }\end{array}$ & $5,923.30$ & $5,487.00$ & $3,582.30$ \\
\hline $\begin{array}{l}\text { Remanente en pastura } \\
(30 \%), \mathrm{KgMS} / \mathrm{ha}\end{array}$ & $1,776.99$ & $1,646.10$ & $1,074.69$ \\
\hline Oferta, KgMS/ha & $4,146.31$ & $3,840.90$ & $2,507.61$ \\
\hline $\begin{array}{l}\text { Demanda de vacas, } \\
\text { KgMS/ha }\end{array}$ & $2,266.06$ & 933.54 & $1,218.45$ \\
\hline Balance, KgMS/ha & $1,880.25$ & $2,907.36$ & $1,289.16$ \\
\hline $\begin{array}{l}\text { Consumo de vaquilla, } \\
\text { KgMS/ha }\end{array}$ & 765.56 & 375.56 & 470.36 \\
\hline Número de vaquillas & 2 & 8 & 3 \\
\hline
\end{tabular}

(1) Número de días promedio del mes: 30 


\section{Conclusiones}

Se concluye que la humedad del suelo constituye uno de los factores relevantes que limita el crecimiento del pasto, ya que siempre estuvo por debajo de la capacidad de campo por deficiencias en las prácticas de riego. Asimismo, la proteína de la pastura superó el requerimiento mínimo para vacas lecheras, a diferencia del aporte energético que se mostró por debajo del mínimo requerido a causa del inapropiado manejo del pastoreo que conduce a la maduración del pasto. Se recomienda la implementación de un riego óptimo de la pastura y de un sistema de rotación de potreros de pastoreo que involucre el número, momento y días de permanencia adecuados; de manera tal que se maximice el crecimiento de pasto y se evite su sub-utilización, y que las vacas consuman un forraje de alta calidad energética que asegure una alta producción de leche.

\section{Literatura citada}

Acuña, H.; Laos, A.; Del Valle, O. y F. San Martín. 1978. Evaluación del Rendimiento y del Valor Nutritivo de los Pastos Cultivados. Informe Anual 1978. IVITA/ Universidad Nacional Mayor de San Marcos. Lima Perú.

A.O.A.C. 1980. Official Methods of Analysis (9th. De.). Association of Agricultural Chemists. Washington, D.C. 832 pp.

Bojorquez, C. 1989. Alimentación del Ganado Lechero en base a Pasturas (Sierra). En: Simposium de producción de vacunos de leche en el Perú. XII Reunión Científica Anual de la APPA. Lima - Perú.

Calzada, B. J. 1982. Métodos Estadísticos para la Investigación. Quinta Edición. UNALM.

Geenty, K. G. and Rattray, P. V. 1987. Energy Requirements of Grazing Sheep and Cattle. In: Livestock Feeding on Pasture. Ocasional Publication Nro. 10. 145 pp.

Korte, C.J.; Chu, A.C.P. and Field, T. R. O. 1987. Pasture Production. In: Livestock Feeding on Pasture. Occasional Publication. Nro. 10. 145 pp.

Ñaupari, V. J. y Flores, M. E. 1996. Análisis y Diseño de Planes de Alimentación en Pasturas. IV Congreso Nacional de Ingenieros Zootecnistas. Huancayo (Junín).

Ñaupari, V.J. 2000. Variación Estacional en el Consumo, Valor Nutritivo y Perfil Alimentario de Vacas Lecheras en la Unidad de Producción Consac de la SAIS Túpac Amaru Ltda. $\mathrm{N}^{\circ} 1$. Tesis Magister en Producción Animal. Universidad Nacional Agraria La Molina. Lima - Perú.

San Martín, F.; Acuña, H.; Laos, A. y Del Valle, O. 1974. Valor Nutritivo de los Pastos Cultivados: Lolium perenne y Lolium multiflorum. Rev. Inv. Pec. (IVITA). UNMSM. 5(1). 21 -26.

San Martín; Laos, A.; Huasasquiche, A. y Navas, M. 1980. Valor Nutritivo de los Pastos Cultivados: Lolium perenne y Lolium multiflorum. Rev. Inv. Pec. (IVITA). UNMSM. 5(1). $21-26$.
Van Soest, P. J. 1985. Composition, Fiber Quality and Nutritive Value of Forages. In: Forages the Science of Grassland and Agriculture. Iowa State University Press. Ames. USA. 